\title{
Ensino de infografia baseada em narrativas pessoais
}

\author{
Teaching infographics based on personal narratives
}

\author{
Anelise Zimmermann, Sara Copetti Klohn
}

Infografia, narrativas pessoais, design de informação, educação

O artigo apresenta um estudo realizado a partir de atividades de ensino de infográficos baseados em narrativas pessoais. Este estudo ocorreu em um curso de graduação e um curso de especialização, ambos em design gráfico, durante o ensino remoto devido à pandemia de Covid-19 (2020-2021). Nas atividades, após a introdução e discussão de conteúdo teórico, as/os alunas/os escolheram temas individuais particulares às suas rotinas, coletaram e analisaram dados, realizaram estudos de representação visual das informações e desenvolveram o projeto final. Durante todo o processo, as/os alunas/os mantiveram um diário para o registro de suas etapas de trabalho, anotações de autorreflexões e questionamentos. O resultado da atividade e as informações coletadas nos diários foram então categorizados e analisados pelas pesquisadoras de acordo com as etapas do processo e estruturas visuais. Os resultados mostraram que as atividades provocaram bastante interesse pelo processo de coleta e organização de dados, de forma extensiva e variada, gerando engajamento das/os estudantes e autorreflexão sobre as formas de representação das informações. Para o aprimoramento das atividades em aplicações futuras, sugere-se que sejam estimuladas alternativas mais variadas de representações visuais.

Infographics, personal narratives, information design, education

This paper presents a study about teaching infographics using learning activities based on personal narratives. This study happened in two graphic design courses, one undergraduate and one postgraduate, during an online teaching period that happened due to the Covid-19 pandemic (2020-2021). Initially, the lecturers introduced theoretical content about the subject by. Then, the students selected their themes, collected and analyzed data related to aspects of their routines, sketched visual alternatives, and designed the final infographics. During the process, the students kept a reflective log to register their progress, reflections, and questions. The information collected on their logs was then categorized and analyzed by the researchers. The goal was to determine the contributions of these activities for teaching infographics, exploring subjectivity, and engaging students in the online learning mode. The results showed that students were motivated by working with personal narratives; the data collection was extensive and diverse, demonstrating students' engagement with the project. For improving the exercise, students could be stimulated to develop unusual visual representation.

\section{Introdução}

Enquanto infográficos são comumente definidos por sua objetividade, designers, artistas, e profissionais variados têm cada vez mais contado histórias através de narrativas visuais, que podem ser categorizadas como infográficos, mas que envolvem subjetividade. Sites como vis 4 me.com e flowingdata.com são característicos do crescente uso destas representações

Anais do $10^{\circ} \mathrm{CIDI}$ e $10^{\circ} \mathrm{CONGIC}$

Kelli C.A.S. Smythe, Rafael de Castro Andrade (orgs.)

Sociedade Brasileira de Design da Informação - SBDI

Curitiba | Brasil | 2021
Proceedings of the $10^{\text {th }} \mathrm{CIDI}$ and $10^{\text {th }}$ CONGIC

Kelli C.A.S. Smythe, Rafael de Castro Andrade (orgs.)

Sociedade Brasileira de Design da Informação - SBDI Curitiba | Brazil | 2021 
visuais e são utilizados por Thudt e colegas (2017) para análises do uso da subjetividade no processo de desenvolvimento de tais narrativas. Este tipo de infográfico, de abordagem pessoal, é mais livre que os infográficos tradicionais, no sentido que permite a interpretação subjetiva em alguns aspecto, não primando pela exatidão dos dados, mas concentrando-se na experimentação de representações visuais. Narrativas pessoais podem ser utilizadas em exercícios exploratórios de comunicação visual, no estudo de análise de dados com sua tradução em informações visuais compreensíveis e em experimentações de linguagens visuais variadas. É importante ressaltar que subjetividade aqui é vista como apontado por Thudt et al. (2017), referindo-se a escolhas feitas pelo designer para comunicar perspectivas pessoais, sentimentos e experiências, e não diz respeito à apresentação deliberada de dados falsos.

Como base neste tema, este artigo apresenta parte dos resultados da pesquisa $O$ ensino $e$ práticas do desenho aplicado ao Design de Informação em Design Gráfico. A metodologia desta pesquisa é de natureza qualitativa, descritiva, do tipo exploratória e foi desenvolvida a partir de levantamento bibliográfico e da descrição e análise de dados coletados em atividades pedagógicas. As atividades foram realizadas no Curso de Design Gráfico da Universidade do Estado de Santa Catarina e na Especialização em Design da Universidade Federal do Rio Grande do Sul entre 2019 e 2021. Os dados foram coletados por meio de diários, elaborados pelas acadêmicas e acadêmicos ao longo das atividades. Para a categorização dos dados, foi utilizado o Framework para Design de Infográficos aplicado ao projeto de narrativas pessoais, com base em Rajamanickam (2005).

\section{Infografia e narrativas visuais pessoais}

Inicialmente, neste tópico, são discutidos aspectos dos infográficos, suas narrativas visuais e métodos de projeto. Em seguida, são abordados conceitos e exemplos da infografia de narrativas pessoais.

\section{Infografia - definição, narrativas e métodos}

Infográficos são artefatos que integram imagens e texto com o intuito de informar e comunicar uma mensagem de forma clara e objetiva para facilitar o entendimento de um assunto geralmente complexo (Carvalho \& Aragão, 2012; Lima, 2015; Lyra, Reis, Cruz, \& Isotani, 2019). De dados quantitativos a acontecimentos, infográficos podem abordar grande variedade de assuntos (Carvalho \& Aragão, 2012; Fetter \& Scherer, 2010). Eles "revelam o escondido, explicam o complexo, e iluminam o obscuro" (Rajamanickam, 2005, p. 2).

A estrutura e o conteúdo dos infográficos determinam a sua narrativa ${ }^{1}$. Neste artigo, quando se fala em narrativa visual, refere-se aos modos como os elementos visuais contam a "história" do infográfico. Em elementos visuais também incluem-se as informações verbais gráficas,

\footnotetext{
${ }^{1}$ Segundo Vieira et al. (2019) há uma falta de consenso quanto ao uso do termo "narrativa" referente a infográficos nas publicações em pesquisa em Design no Brasil. Assim sendo, o presente artigo não adentra na discussão ampla do termo.
} 
conforme definição de Twyman (1985), que incorporam a escrita como elemento que também é percebido visualmente, assim como os elementos pictóricos e esquemáticos. Como história, entende-se aqui a mensagem comunicada para os leitores. Esta mensagem é compreendida através das informações visuais representadas, assim como pela sua disposição na página.

Formalmente, infográficos geralmente são constituídos por diagramas, o que permite, muitas vezes, que leitores façam uma leitura não-linear, escolhendo o encadeamento da narrativa (Lima, 2015). Do ponto de vista de designers, o infográfico possui estratégias que facilitam a leitura da narrativa. Destas, Rajamanickam (2005) cita o poder de organizar, fazer visível, estabelecer conteúdo, simplificar, adicionar redundância, mostrar causa e efeito, comparar, contrastar e integrar. Para direcionar a atenção dos leitores e orientá-los, Segel e Heer (2010) apontam fatores como: cor, tamanho, orientação, pontos de entrada e continuidade, princípios da Gestalt de agrupamento e contraste de informações e fatores culturais. Ademais, figuras de linguagem também podem ser utilizadas para criar interesse e auxiliar a compreensão dos leitores (Escobar \& Spinillo, 2016). Por fim, a estética é usada para atrair e segurar os leitores no infográfico, além fazer com que a informação seja memorável (Harrison, Reinecke, \& Chang, 2015; Lapolli, 2016).

O processo de construção de um infográfico envolve a seleção de informações, estabelecendo-se relações e padrões dos conteúdos representados de forma compreensível, viabilizando a elaboração de conhecimento por parte de leitores (Rajamanickam, 2005). Aragão e Carvalho (2012, p.174) propõem uma metodologia para desenvolvimento de infográficos que é dividida em três fases: concepção, execução e acabamento. Na primeira fase, define-se o tema que será abordado, onde compreende-se o que é importante comunicar sobre o assunto. Na execução, o conteúdo e a arquitetura de informação são elaborados, focando na hierarquia de informações e composição de elementos gráficos. A última fase, o acabamento, inclui a avaliação do cruzamento do texto com sua representação gráfica, revisões e análise crítica.

Quanto aos conteúdos e formas de apresentação visual de infográficos, Rajamanickam (2005) estabelece o Framework para Design de Infográficos (Infographic Design Framework), no qual são classificados o tipo de informação, o dispositivo de infográfico e o método de comunicação. O tipo de informação pode ser espacial, cronológico ou quantitativo. $O$ dispositivo abrange as formas de representação visual dos conteúdos, sendo subdividido em diagramas (ícones, sequência, processo, linha do tempo e exposição), mapas (localizador, de dados, esquemático) e gráficos (fluxo, barra, pizza, organizacional). O método comunicacional do infográfico pode ser estático, em movimento ou interativo.

Para o estudo apresentando neste artigo, as fases iniciais de concepção e execução de infográficos de Aragão e Carvalho (2012) foram consideradas mais importantes que o acabamento; já o Framework de Rajamanickam (2005) é usado como base para descrever e analisar as atividades realizadas de acordo com suas etapas e formatos. 


\section{Narrativas visuais pessoais}

Thudt et al. (2017) classificam narrativas visuais pessoais como representações visuais que contam histórias de experiências particulares do ponto de vista do narrador. Neste artigo, estas narrativas são também consideradas infográficos, já que incluem a combinação de texto e imagem para comunicar uma mensagem, mesmo que não de forma objetiva. Além dos websites supracitados, que compilam vários exemplos de infográficos de narrativas pessoais, dois outros exemplos expressivos são discutidos a seguir para contextualizar este tipo de artefato: o trabalho de Jaime Serra e o projeto Dear Data das designers Giorgia Lupi e Stefanie Posavec.

Jaime Serra é um jornalista e infografista que tem seus infográficos publicados em diversos jornais do mundo e realiza exposições artísticas de suas narrativas visuais. Sua infografia é rica em subjetividade mesmo quando trata de assuntos objetivos, pois inserem metáforas visuais. Atuando como colunista de jornais, ele inova ao opinar e contar histórias em forma de infográfico, colocando a narrativa visual como foco principal. A Figura 1 mostra dois exemplos de infográficos de narrativas pessoais desenvolvidos por Serra. O primeiro, mostra o seu consumo de café ao longo de um ano, representado pelas manchas do líquido feitas com a base da xícara; o segundo mostra o que os convidados de sua festa de 50 anos desejaram a ele, sendo esses desejos identificados por confetes coloridos (saúde em azul, amor em rosa, e dinheiro em verde). Ambos os exemplos não mostram dados exatos, mas visualmente atribuem valores a períodos de maior e menor consumo de café, pela quantidade de manchas feitas no papel, e da proporção de desejos de saúde, amor e dinheiro ao aniversariante, pela quantidade de confetes de cada cor.

Figura 1: Infográficos de narrativas pessoais de Jaime Serra - adaptações de obras originais para a publicação na revista Cultura. Da esquerda para a direita: (A) Café a diario, (B) Salud, Dinero o amor. Fonte: Flickr de Jaime Serra

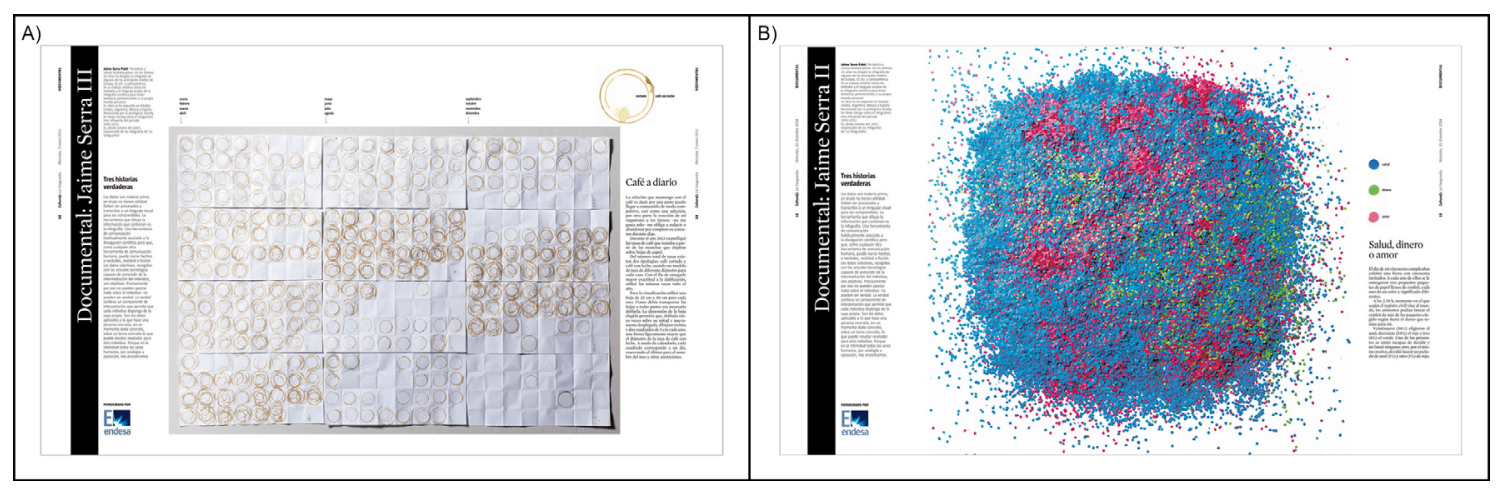

No projeto Dear Data (www.dear-data.com), as designers Giorgia Lupi e Stefanie Posavec trocaram cartões postais semanalmente, durante o período de um ano, onde contaram aspectos de suas vidas através de dados pessoais coletados (Figura 2). Os dados foram representados de formas variadas na frente dos cartões postais, e no verso foram inseridas as legendas para a leitura dos infográficos. A coletânea de seus cartões postais virou livro (Lupi \& 
Posavec, 2016) e, posteriormente, parte da coleção foi adquirida pelo Museu de Arte Moderna de Nova lorque (MoMA, 2015). A Figura 2 mostra dois exemplos dos cartões, frente e verso, ambos representando os dados referentes a risadas dadas ao longo de uma semana. $\mathrm{Na}$ esquerda (Figura 2A), Lupi registrou seus dados através de formas que se assemelham a pétalas de flores. Já, no postal da direita (Figura 2B), Posavec utilizou elipses e linhas em diferentes cores representando risadas de diferentes intensidades.

Figura 2: Cartões postais do projeto Dear Data: A week of laughter. Fonte: website Dear Data

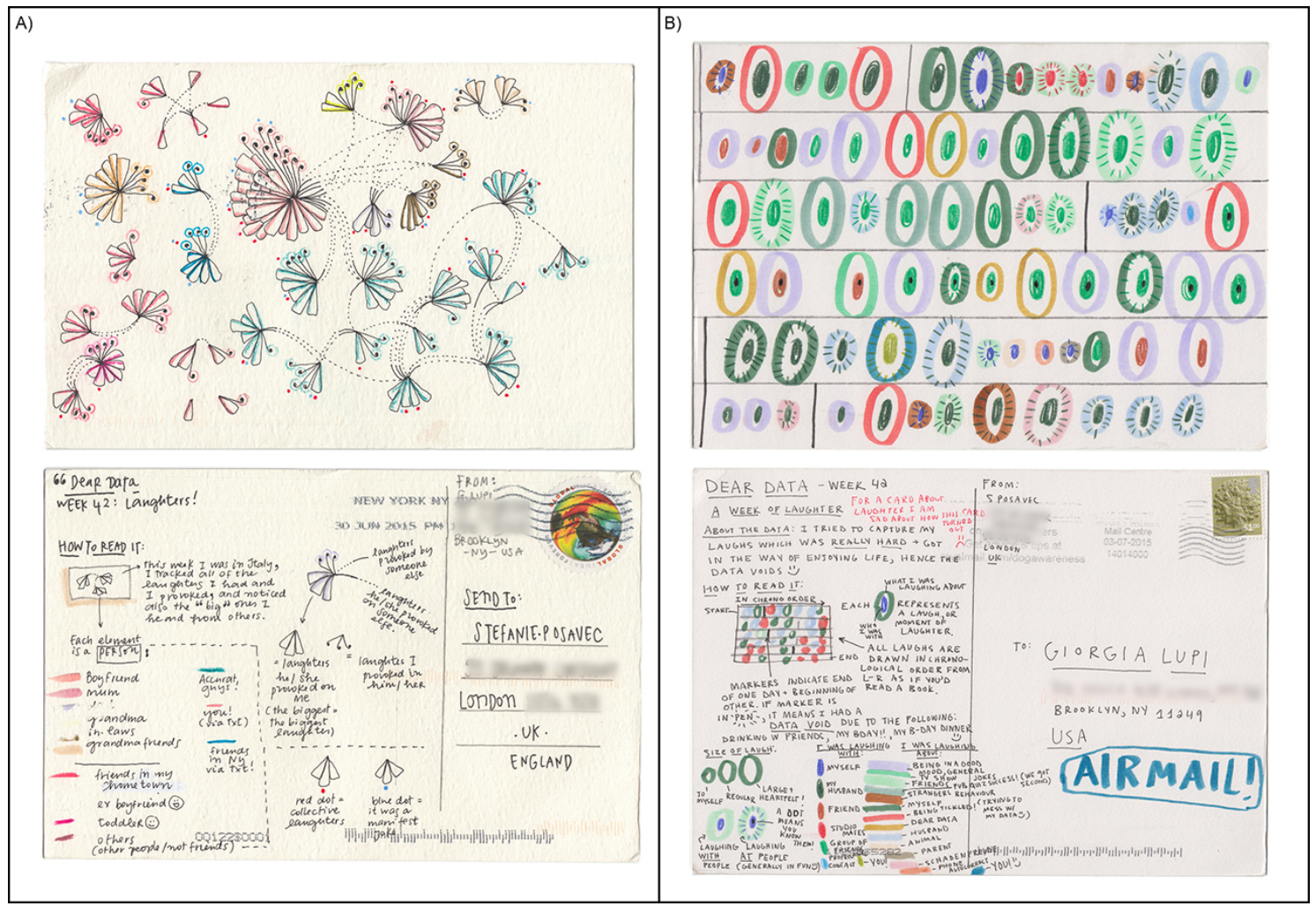

Parte do processo de elaboração dos infográficos também foi registrado e publicado pelas autoras, o que pode ser visualizado na Figura 3. Além disso, junto aos esboços, também foram compartilhadas reflexões em forma de texto, as quais funcionaram como um diário pessoal. A possibilidade de observar esses estudos e anotações é interessante por permitir a aproximação de leitores com o momento em que as informações foram coletadas e, por meio dos esboços, seguir a sequência de ideias e relações estabelecidas no decorrer do processo.

Lupi (Dear Data, n.d.) explica a relação entre suas reflexões sobre o ato de rir e as formas de representações visuais (Figura $3 \mathrm{~A}$ ). 
In my postcard, I wanted to convey the idea that laughing creates a connection and a bound between the people involved, so I conceived my data as "networked", as I never do actually. So I created nodes to represent each single person, and dotted arcs to link those guys who were laughing together, indicating the "instigator" with a solid line. ${ }^{2}$

Nesta fala, observa-se que essas representações vão bem além de informações quantitativas e possuem nuances que podem passar despercebidas em uma leitura superficial. Estes mesmos detalhes também podem levar a outras interpretações, visto que não são tratados de forma objetiva ou representados por meio de dispositivos convencionais de infográficos.

Figura 3: Estudos para os cartões postais $A$ week of laughter do projeto Dear Data.

Fonte: website Dear Data

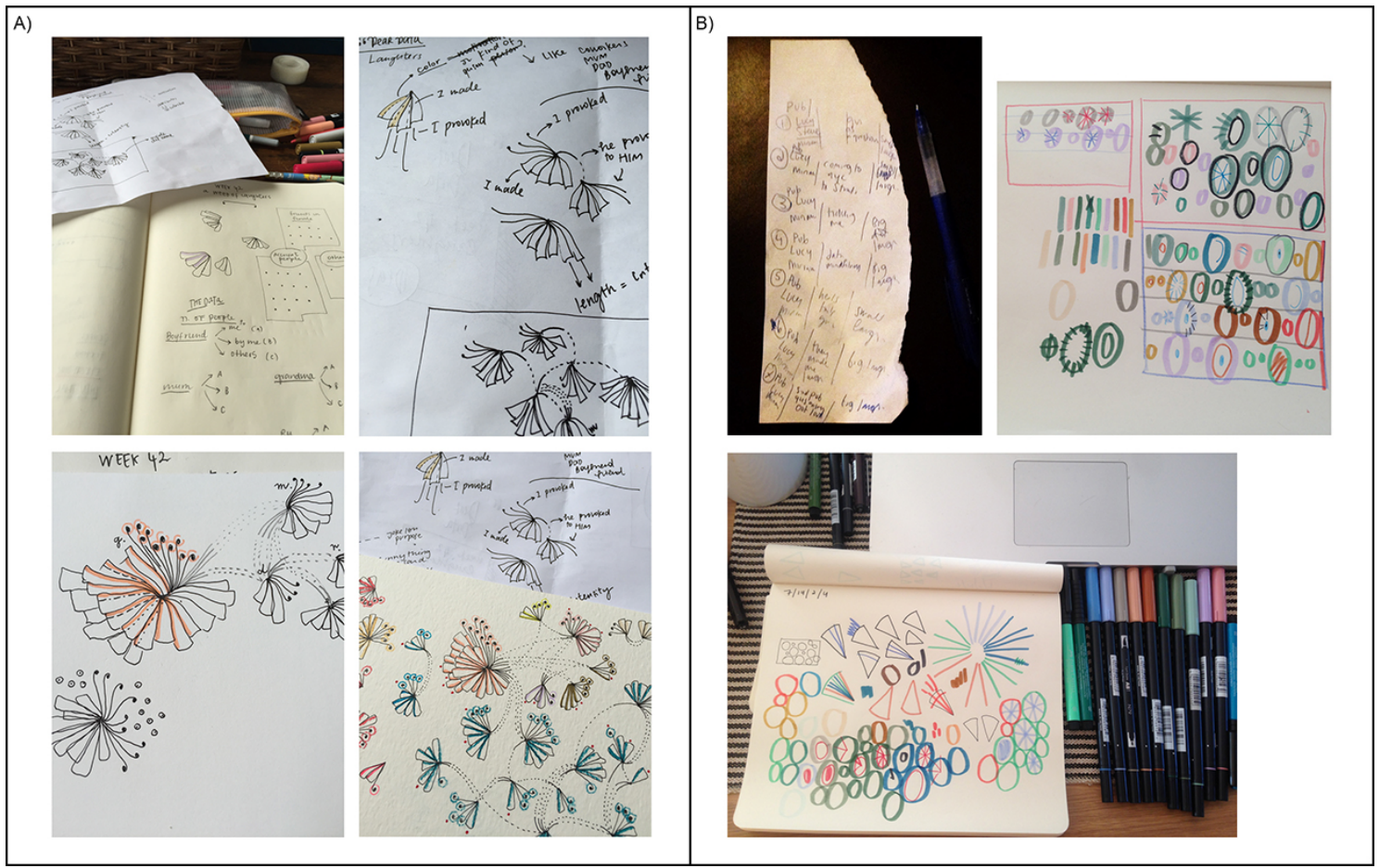

Para analisar o processo de desenvolvimento desse tipo de narrativas, Thudt et al. (2017) focaram em que momento ocorre a introdução de subjetividade. Para isso, eles identificaram as técnicas utilizadas para introduzir a subjetividade em cada etapa do processo, conforme a Tabela 1 a seguir.

\footnotetext{
2 "No meu cartão postal, eu queria transmitir a ideia de que rir cria uma conexão e um limite entre as pessoas envolvidas, por isso concebi meus dados como "em rede", o que nunca fiz na verdade. Por isso, criei nós para representar cada pessoa individualmente, e arcos pontilhados para ligar aquelas pessoas que estavam rindo juntas, indicando o "instigador" com uma linha sólida." Tradução nossa.
} 
Tabela 1: Resumo das técnicas utilizadas para introduzir subjetividade em narrativas visuais pessoais, adaptado de Thudt et al. (2017).

\begin{tabular}{ll}
\hline Etapa de criação & Técnica utilizada para expressar perspectivas subjetivas \\
\hline Coleta de dados & Coleta de dados subjetiva \\
& Captura seletiva de dados \\
& Reconstrução de dados pela memória \\
\hline Processamento dos dados & Escolha de aspectos específicos dos dados \\
& Aglomeração de dados em grupos de significação pessoal \\
& Inferir dados faltantes \\
\hline Mapeamento visual & Metáforas visuais para experiência \\
& Codificação baseada em teorias psicológicas \\
& Uso poético de codificações não convencionais \\
\hline Apresentação & Anotações \\
& Mídia como informação contextual \\
& Estilo e escolha de material \\
\hline
\end{tabular}

Percebe-se que a introdução da subjetividade, independente da etapa em que ocorra, não significa dados falsos ou enganosos, ela apenas é parte do processo de desenvolvimento de narrativas pessoais. A seguir, serão apresentadas e discutidas as atividades acadêmicas práticas desenvolvidas a partir desse tipo de proposta.

\section{Desenvolvendo infográficos baseados em dados pessoais: atividades em cursos de design gráfico}

Foram desenvolvidas atividades de narrativa pessoal por meio de infográficos com duas turmas, sendo uma de graduação, da segunda fase do curso de Design Gráfico da Universidade do Estado de Santa Catarina, e uma de especialização em Design Gráfico da Universidade Federal do Rio Grande do Sul, a qual possuía estudantes com formações diversas. Com base no perfil dos alunos e alunas e das limitações técnicas provenientes no isolamento social, deuse maior ênfase às etapas de concepção e execução do projeto (Aragão e Carvalho, 2012), sendo que a etapa de acabamento precisou ser adequada às condições de cada estudante (acesso a materiais, conhecimento de software). Aqui são apresentadas as etapas e resultados de quatro estudantes, sendo dois/duas da graduação e dois/duas da especialização.

A proposta inicial de projeto foi o registro de experiências pessoais durante o período da pandemia de Covid-19 (2020-2021). As experiências podiam envolver questões relativas a atividades diárias e emoções, a partir da observação de suas rotinas e anotação de repetições ou maneiras de realizar tarefas, a fim de gerar um infográfico.

A atividade foi composta das seguintes etapas:

- Introdução à infografia a partir de conteúdo teórico e exemplos práticos;

- Coleta de dados e instrumentos;

- Organização dos dados, estabelecendo comparações e medidas; 
- Geração de ideias para representação dos dados a partir de associações;

- Seleção de uma alternativa;

- Finalização.

Para o registro das informações foi usada a ferramenta de diário disponível no ambiente virtual de aprendizado Modular Object-Oriented Dynamic Learning Environment (Moodle). Neste diário os alunos deveriam registrar as etapas do projeto e foram incentivados a incluir reflexões, dúvidas e observações sobre suas atividades ao longo do processo.

A seguir são apresentados parte do processo de cada estudante. Em seguida, essas informações são analisadas em conjunto a partir do Framework para Design de Infográficos (Rajamanickam, 2005), incluindo informações sobre o tema de cada atividade e a forma de coleta dos dados.

\section{Estudante 1: Infográfico "O corpo e seus sentimentos"}

Nesse infográfico a/o Estudante 1 registrou seus sentimentos ao longo de uma semana, divididos em três grandes categorias: felicidade, tristeza e agradecimento (Figura 4). Por exemplo, para felicidade ela/e considerou sentimentos como ânimo, motivação e tranquilidade, enquanto agradecimento foi definido por sentimentos de amor, gratidão e admiração. Convém salientar que, para outra pessoa, o amor, por exemplo, poderia ser visto como felicidade e a tranquilidade, como agradecimento. Portanto, a questão da subjetividade é pessoal e abre espaço para reflexões, o que também era o propósito do infográfico, ou seja, a identificação e caracterização dos diferentes sentimentos de acordo com experiências pessoais ao longo da pandemia. Junto ao registro do processo de trabalho, a/o estudante escreveu:

Gostei de perceber o intervalo de tempo em que minhas emoções se manifestam e as possíveis reflexões que podemos fazer em cima disto. Foi interessante perceber como, ultimamente, tenho tido mais momentos ruins que bons, e estes têm se dado ao menos duas vezes por dia. Foi o que me fez querer fazer um paralelo com a situação da pandemia e de como esta está afetando as relações humanas. (Retirado do diário da/o Estudante 1).

A partir dos dados coletados (Figura 4A), as informações foram organizadas por possibilidade de relações, com estudos de representação por meio de dispositivos variados (Figura 4B). Até essa fase, todas as anotações e estudos foram realizados de forma manual. Por fim, a partir da compilação dos dados e seleção de alternativa, foi gerado o resultado (Figura 4C), o qual foi desenvolvido com o uso de ferramentas digitais (softwares gráficos) e analógicas (tintas e papel). 
Figura 4: Processo de desenvolvimento do Infográfico O corpo e seus sentimentos: (A) Coleta de informações; (B) estudos de dispositivos; e (C) versão final do infográfico. Fonte: Imagens coletadas no diário, 2021 (uso de imagens concedido pelo/a autor/a)

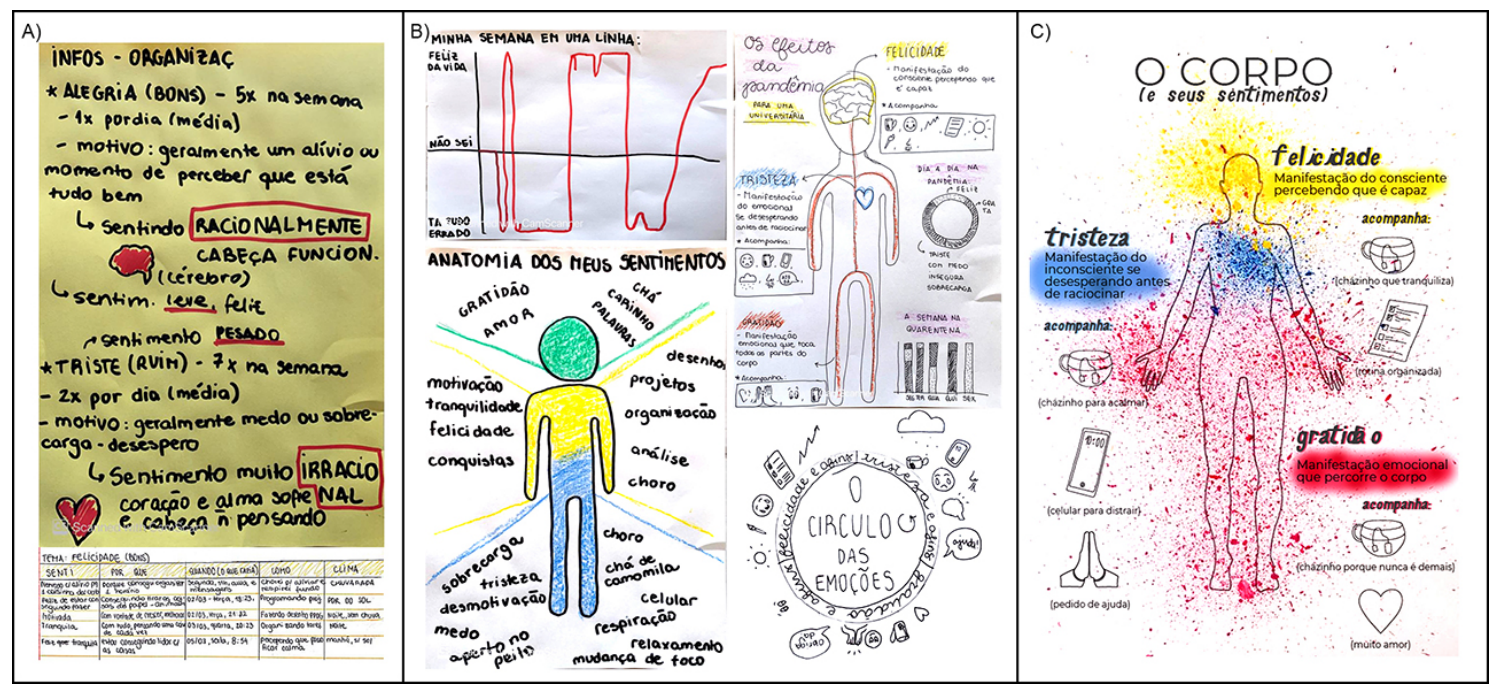

Observando o processo de projeto, identificaram-se duas tentativas de realizar gráficos analíticos (Figura 4 B), a primeira com dois extremos (feliz da vida e está tudo errado); e a segunda mostrando uma soma das emoções. Estas duas opções seriam maneiras de objetivar dados subjetivos. As outras duas opções de estudos relacionam os sentimentos com partes do corpo, uma maneira subjetiva de representar os dados, pois também depende do ponto de vista do/a autor/a. Estas opções subjetivas, resultaram na solução do projeto, que mostra os respingos de tinta para demarcar regiões, mesmo que a intensidade ou quantidade de respingos não indique dados exatos. Para a/o Estudante 1, os respingos de tinta mostram "como os sentimentos respingam nas ações"; para os leitores, talvez esta intenção não seja percebida e outra interpretação possa ser dada. Aqui, a subjetividade do processo e da representação dá margem também à leitura subjetiva, o que pode ser bastante adequado quando o tema tratado se refere a sentimentos e emoções.

\section{Estudante 2: Infográfico "É natural? Jornada Capilar"}

No infográfico a seguir, a/o Estudante 2 tomou como ponto de partida as mudanças de cores e comprimentos de cabelo durante o período da pandemia, estabelecendo relações com experiências de anos anteriores, incluindo emoções, atividades e fatos que podem ter influenciado estas mudanças (Figura 5). Novamente, as etapas de projeto são as mesmas do projeto anterior (Estudante 1), sendo que, parte dos dados foram inferidos a partir da memória, o que indica a subjetividade na etapa de coleta de dados (conforme Tabela 1).

Nesta etapa, o/a estudante usou como categorias: ano/meses, fatos importantes ao longo desse período, comprimentos de corte de cabelo e cores (Figura 5A). Nos estudos de representação foram testados diferentes dispositivos, como o diagrama de exposição e o diagrama de linha do tempo. Também foi testada a técnica de representação, com a coloração 
de cabelos de bonecas e a sua digitalização por meio da fotografia (Figura 5B). O resultado é composto por três dispositivos de dados: a linha do tempo, o gráfico de fluxo e o gráfico de barras, sendo que as informações dos três dispositivos se conectam pelas cores utilizadas (Figura 5C). Além disso, na linha do tempo também foi utilizado o recurso do balão de conversa, através dos quais o/a estudante registrou reflexões e indagações pessoais sobre as razões das mudanças de cabelo. Assim, apesar do infográfico apresentar elementos que indicam certa precisão de informações (datas, porcentagens), ele também deixa visível a subjetividade por meio dessas indagações e testemunhos.

Figura 5: Processo de desenvolvimento do Infográfico É natural? Jornada Capilar: (A) Coleta de informações; (B)estudos de dispositivos; e (C) versão final do infográfico. Fonte: Imagens coletadas no diário, 2021. (uso de imagens concedido pelo/a autor/a)

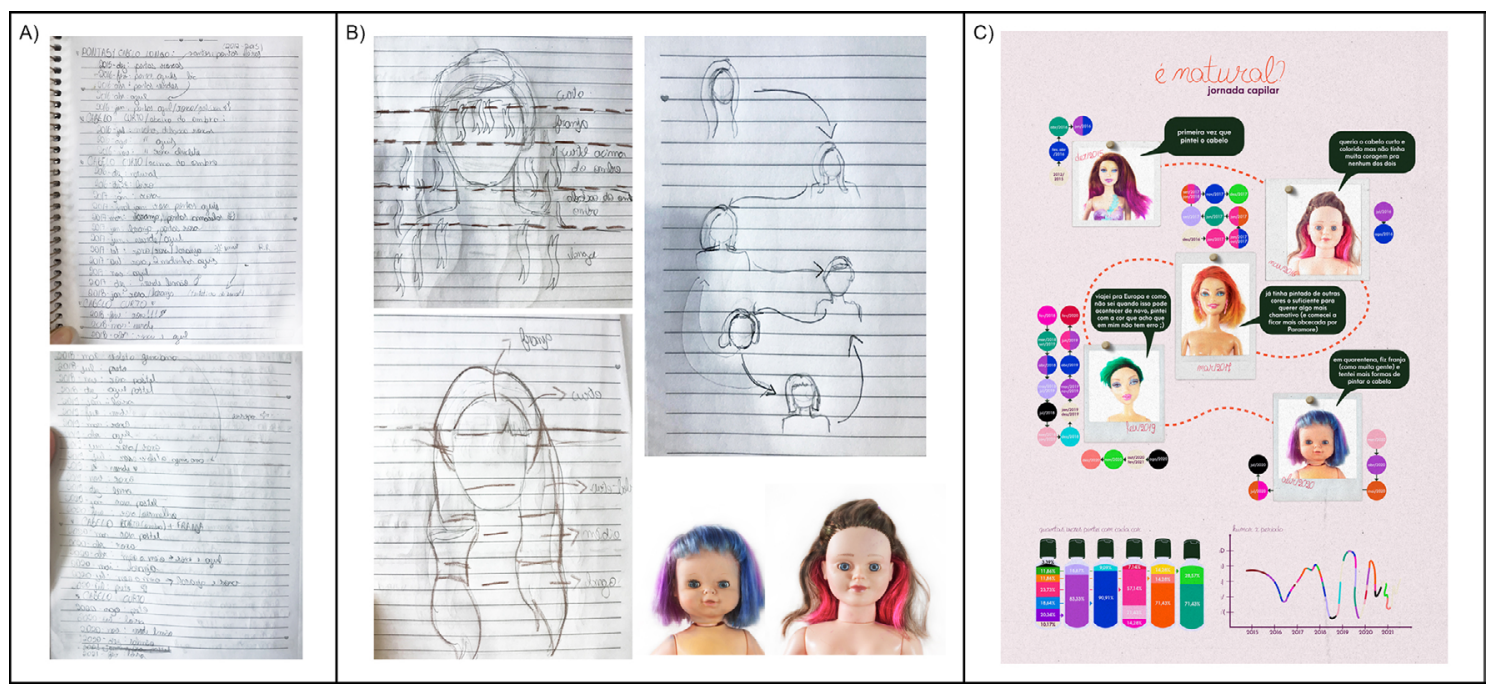

\section{Estudante 3: Infográfico "Minha rotina"}

Neste projeto, a/o Estudante 3 teve como objetivo registrar as ações do dia a dia, considerando o contexto da pandemia, de isolamento social, e os cuidados com um bebê recém-nascido (Figura 6). Segundo a/o estudante, esse projeto serviu como forma de observar, com mais atenção, os afazeres diários repetitivos que muitas vezes passam despercebidos e, a partir dessas observações, estabelecer relações entre essas atividades e níveis de humor e estresse.

A/o estudante fez uma coleta de dados extensiva e precisa das atividades realizadas durante quatro dias, distribuídas em vinte e quatro horas. Ela/e estabeleceu um comparativo das oscilações dos níveis de estresse ao longo desse período, buscando objetividade durante todo processo, mesmo que mesclando dados objetivos e subjetivos. Por exemplo, foram anotados os horários precisos de todas as atividades com o bebê ao longo da semana, ao mesmo tempo que foram atribuídos níveis de valor para as sensações de estresse e tranquilidade no decorrer dessas atividades (Figura 6A). Entende-se que a definição e registro das ações do dia é mais objetiva do que a percepção e registro do humor. Para esses registros, a/o estudante, fez as anotações dos dados no celular por tê-lo sempre próximo, e 
posteriormente os transcreveu para o papel, buscando garantir uma maior precisão na coleta, o que demonstra sua preocupação com o processo.

Figura 6: Processo de desenvolvimento do Infográfico Minha rotina: (A) Coleta de informações; (B) estudos de dispositivos; (C) e versão final do infográfico. Fonte: Imagens coletadas no diário, 2020. (uso de imagens concedido pelo/a autor/a)

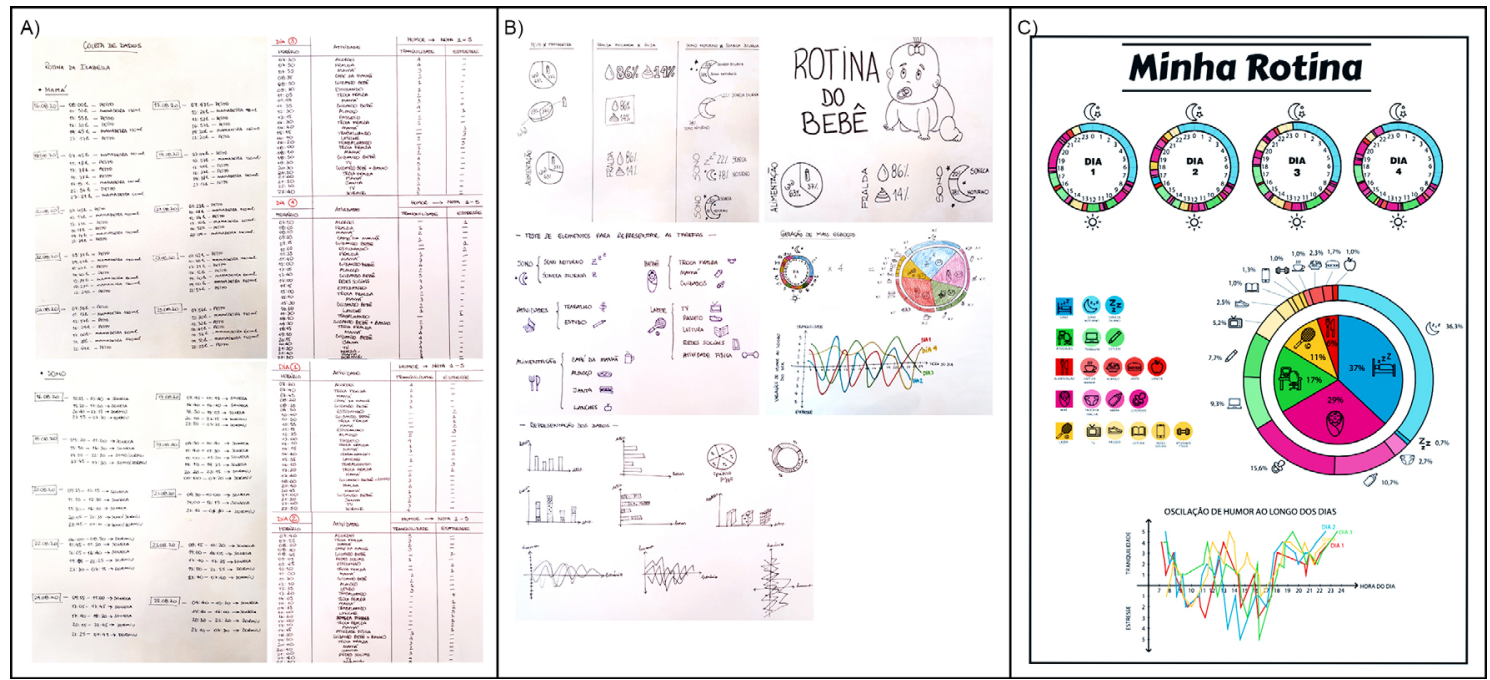

$\mathrm{Na}$ etapa de estudos de dispositivos, foram testados diferentes formatos para a representação dos dados, sendo que para o resultado foram utilizados gráficos de pizza e um gráfico de fluxo, todos desenvolvidos a partir da ilustração vetorial. A versão final possui um formato bastante convencional, com o uso de ícones, não utilizando elementos visuais subjetivos relacionados ao tema.

\section{Estudante 4: Infográfico "Sempre a caminho da pia"}

Para esta atividade, o/a Estudante 4 optou por registrar as informações relativas à ação constante de lavar a louça durante o período de um mês de isolamento social da pandemia de Covid-19, com foco nos tipos de utensílios lavados e suas frequências de uso (Figura 7). Esses dados também foram comparados a outras atividades do dia a dia, as quais sofreram alterações ao longo do período de seis meses da pandemia, incluindo horário de acordar, local de trabalho, hábitos de alimentação, tipos de lazer e horário de dormir.

Para os estudos de dispositivo, foi gerada apenas uma alternativa (registrada no diário), a qual foi trabalhada na proposta final, tendo como base a fotografia da pia e do escorredor de louça (diagrama de exposição e gráfico de barra), a fotografia de um quadro de giz (diagrama de ícones) e textos adicionais inseridos por meio de softwares gráficos. 
Figura 7: Processo de desenvolvimento do Infográfico Sempre a caminho da pia: (A) Coleta de informações; (B) estudos de dispositivos; e (C) versão final do infográfico. Fonte: Imagens coletadas no diário, 2020. (uso de imagens concedido pelo/a autor/a)

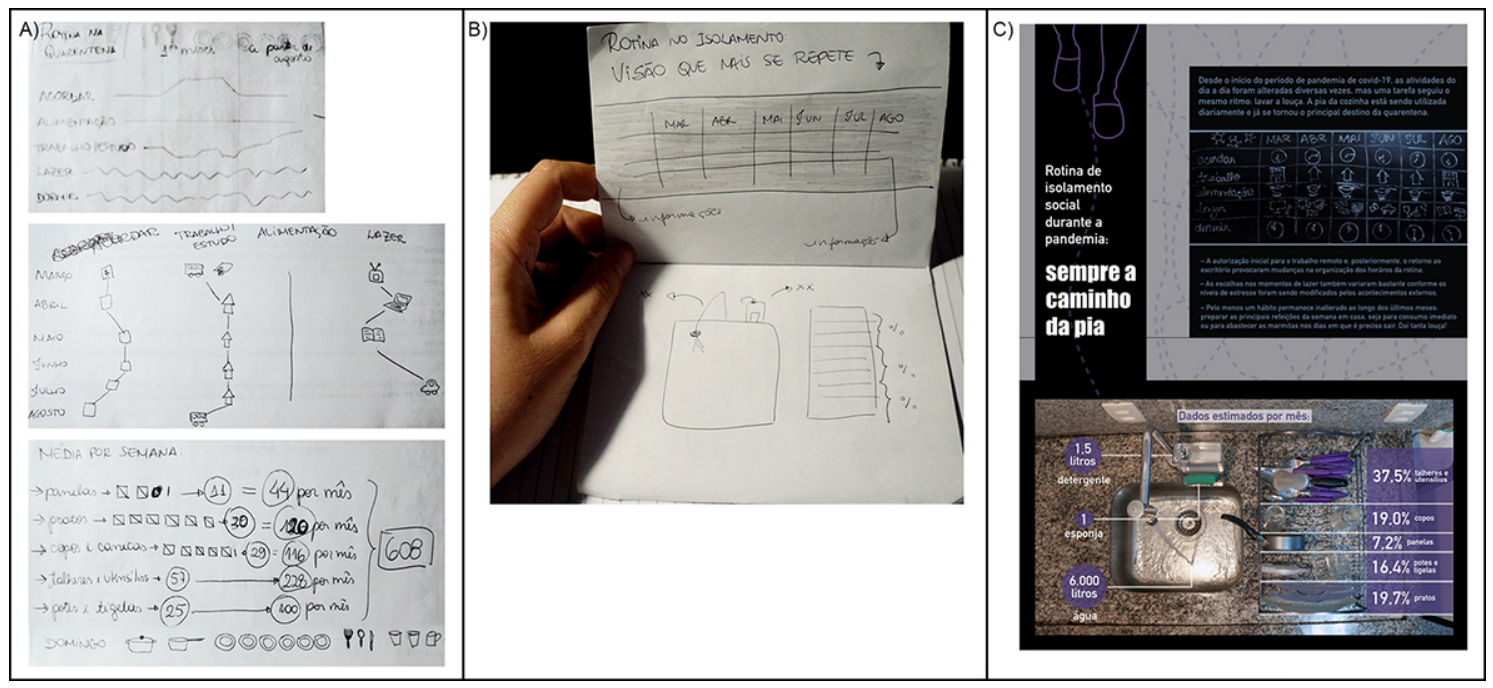

Observa-se que a coleta de dados foi feita a partir de uma média semanal (louça lavada) e reconstrução de dados pela memória (outras atividades realizadas no período de seis meses). Assim, entende-se que o/a estudante fez uso da subjetividade para inferir parte dos dados, os quais referem-se especificamente a sua rotina.

\section{Análise das atividades a partir do Framework para Design de Infográficos}

A seguir, as informações referentes às atividades descritas foram organizadas com base no Framework para Design de Infográficos (Rajamanickam, 2005). Ao modelo original foram incluídas as categorias "tema" e "forma de coleta de dados", conforme a Tabela 2.

Tabela 2: Framework para Design de Infográficos aplicado ao projeto de narrativas pessoais (com base em Rajamanickam, 2005)

\begin{tabular}{lllll}
\hline & Estudante 1 & Estudante 2 & Estudante 3 & Estudante 4 \\
\hline Tema & $\begin{array}{l}\text { Emoções ao longo } \\
\text { da semana: os } \\
\text { efeitos da pandemia } \\
\text { para uma } \\
\text { universitária }\end{array}$ & $\begin{array}{l}\text { As cores e cortes } \\
\text { de cabelo na } \\
\text { pandemia } \\
\text { comparadas com } \\
\text { outros períodos }\end{array}$ & $\begin{array}{l}\text { Cuidados com a/o } \\
\text { bebê de 4 meses } \\
\text { (trocar fralda, dar } \\
\text { mamá, dar } \\
\text { mamadeira, dar } \\
\text { banho, rotina do } \\
\text { sono, etc.) }\end{array}$ & $\begin{array}{l}\text { Atividade de lavar a } \\
\text { louça durante a } \\
\text { pandemia } \\
\text { (quantidade e tipo } \\
\text { de utensílios) }\end{array}$ \\
\hline $\begin{array}{l}\text { Forma de } \\
\text { coleta de } \\
\text { dados }\end{array}$ & $\begin{array}{l}\text { Tabela } \\
\text { (anotações de }\end{array}$ & $\begin{array}{l}\text { Categorização } \\
\text { frequência) } \\
\text { cronológicas } \\
\text { e de frequência) }\end{array}$ & $\begin{array}{l}\text { Tabela } \\
\text { (anotações } \\
\text { cronológicas } \\
\text { e de frequência) }\end{array}$ & $\begin{array}{l}\text { (anotações } \\
\text { cronológicas } \\
\text { e de frequência) }\end{array}$ \\
\hline $\begin{array}{l}\text { Tipo de } \\
\text { informação }\end{array}$ & Espacial & $\begin{array}{l}\text { Cronológica e } \\
\text { Quantitativa }\end{array}$ & Quantitativa & $\begin{array}{l}\text { Quantitativa e } \\
\text { Espacial }\end{array}$ \\
\hline $\begin{array}{l}\text { Dispositivo } \\
\text { do }\end{array}$ & Diagrama de & $\begin{array}{l}\text { Diagrama de Linha } \\
\text { do tempo }\end{array}$ & $\begin{array}{l}\text { Gráfico de Pizza } \\
\text { Gráfico de Fluxo }\end{array}$ & $\begin{array}{l}\text { Gráfico de barra } \\
\text { Diagrama de }\end{array}$ \\
\hline
\end{tabular}




\begin{tabular}{lllll}
\hline infográfico & $\begin{array}{l}\text { Gráfico de Fluxo } \\
\text { Gráfico de Barras }\end{array}$ & Diagrama: Ícones & $\begin{array}{l}\text { Exposição } \\
\text { Diagrama: Ícones }\end{array}$ \\
\hline $\begin{array}{l}\text { Método de } \\
\text { comunicação }\end{array}$ & Estático & Estático & Estático & Estático \\
\hline
\end{tabular}

A partir desta classificação, observou-se que uma mesma proposta de atividade originou usos variados de formas de coleta de dados, tipos de informação representadas e dispositivos de infográfico.

\section{Discussão}

As experiências das atividades foram consideradas produtivas e promissoras enquanto ensino de narrativas visuais e infográficos, suscitando uma série de conteúdos e abordagens a serem exploradas. Os pontos positivos e aspectos a serem melhorados são discutidos a seguir.

Pode-se destacar positivamente o interesse e engajamento das/os estudantes nas atividades, por se tratar da representação de assuntos particulares ao seu dia a dia. Especialmente durante o momento da pandemia de Covid-19, isolamento social e ensino remoto, o envolvimento dos alunos e alunas foi de extrema importância para o processo de aprendizado. Da mesma forma, a possibilidade de reflexão sobre seus contextos e o compartilhamento dessas informações serviu como uma forma de aproximação de docentes e discentes. Quanto ao processo desenvolvido, foi também positivo o exercício das variadas formas de coleta das informações por parâmetros e categorias definidas pelas/os estudantes, o que possibilitou uma coleta de dados segura e adequada as suas condições em isolamento social.

Já o uso do recurso do diário no registro de processo de trabalho se mostrou bastante fértil, visto que permitiu não só os registros em diferentes formatos (imagens, texto, vídeo, áudio, links), como também auxiliou na comunicação entre as partes e o acompanhamento do processo ideacional, criativo e reflexivo ao longo do processo.

Tendo sido as primeiras experiências das docentes com este tipo de abordagem do conteúdo, também se percebeu a necessidade de ajustes para atividades futuras. Entre eles está a necessidade da adição de mais instruções e conteúdo teórico referentes à coleta, processamento e análise dos dados, visto que foram etapas nas quais as/os estudantes demonstraram grande interesse e empenho. Além disso, promover a análise dos dados por diferentes aspectos pode estimular o pensamento crítico e ampliar o repertório das possibilidades de representação visual dos conteúdos.

Sugere-se também, a ampliação do tempo de experimentações de técnicas não convencionais de representação visual, explorando a subjetividade dos dados coletados visualmente. Percebeu-se que, de modo geral, os alunos inseriram subjetividade na coleta de dados, mas buscaram ser objetivos na representação desses dados, utilizando gráficos de pizza, de barras, ou representações pictóricas um tanto convencionais. Com isso, identificou-se que, os exemplos de infográficos de narrativas pessoais mostrados e discutidos em aula 
(projeto Dear Data e infográficos de José Serra), possuem representações visuais aparentemente simples, porém seus níveis de abstração visual são complexos de se atingir e necessitam tempo de estudo e experimentação.

Por fim, observou-se que o Framework para Design de Infográficos (Rajamanickam, 2005) pode ser ampliado no estudo de infográficos de narrativas pessoais, com a inclusão de novas categorias e perspectivas de análise.

\section{Agradecimento}

Às acadêmicas e acadêmicos da Disciplina de Laboratório de Desenho 2 do Curso de Design Gráfico da Universidade do Estado de Santa Catarina e da Especialização em Design Gráfico da Universidade Federal do Rio Grande do Sul que participaram das atividades apresentadas no artigo e concederam a autorização para a apresentação de seus trabalhos.

\section{Referências}

Carvalho, J. Aragão, I. (2012). Infografia: conceito e prática. InfoDesign, São Paulo 9, 3, 160- 177.

Dear Data. (n.d.). A week of laughter. Disponível em http://www.dear-data.com/week-42-aweek-of-laughter

Escobar, B. T. De, \& Spinillo, C. G. (2016). Retórica visual na infografia sobre saúde. InfoDesign. Revista Brasileira de Design Da Informação, 3(2), 162-179.

Fetter, L., \& Scherer, F. (2010). Infografia: o Design Visual da Informação. In IX Congresso Brasileiro de Pesquisa e Desenvolvimento em Design. Retrieved from https://ndga.files.wordpress.com/2010/11/infograficos-fabiano.pdf

Harrison, L., Reinecke, K., \& Chang, R. (2015). Infographic Aesthetics. In Proceedings of the 33rd Annual ACM Conference on Human Factors in Computing Systems, 1187-1190. https://doi.org/10.1145/2702123.2702545

Lapolli, M. Infografia além da subjetividade. Infodesign, São Paulo 13(2), 309-320.

Lima, R. C. (2015). O que é infografia jornalística? InfoDesign - Revista Brasileira de Design Da Informação, 12(1), 111-127. https://doi.org/10.51358/id.v12i1.312

Lupi, G., Posavec, S. (2016). Dear data. New York: Princeton Architectural Press.

Lyra, K. T., Reis, R. C. D., Cruz, W. M., \& Isotani, S. (2019). Um framework de classificação de complexidade para infográficos. Revista Brasileira de Informática na Educação, 27(1), 196223. https://doi.org/10.5753/rbie.2019.27.01.196

Museum of Modern Art. (n.d). Dear data: Moma collection. Disponível em https://www.moma.org/collection/works/215813

Rajamanickam, V. (2005). Infographic Design. Infographics Seminar Handout. Ahmedabad, Bombay. 1-14. http://www.schrockguide.net/uploads/3/9/2/2/392267/infographic_handout.pdf

Segel, E., \& Heer, J. (2010). Narrative visualization: Telling stories with data. IEEE Transactions on Visualization and Computer Graphics, 16(6), 1139-1148.

https://doi.org/10.1109/TVCG.2010.179 
Thudt, A., Perin, C., Willett, W., \& Carpendale, S. (2017). Subjectivity in personal storytelling with visualization. Information Design Journal 23(1), John Benjamins Publishing Company, 48-64.

Twyman, M. (1985). Using Pictorial Language: A Discussion of the Dimensions of the Problem. In T. Duffy \& R. Waller (Eds.), Designing Usable Texts. Orlando: Academic Press.

Vieira, R., Cunha, P., Rolim, E. (2019). Infographics and narrative: exploring concepts. Selected Readings of the 8th Information Design International Conference - Information Design: Memories. São Paulo: Blucher, 27-50.

\section{Sobre as autoras}

Anelise Zimmermann, Dra., Universidade do Estado de Santa Catarina, Brasil <anelise.zimmermann@gmail.com>

Sara Copetti Klohn, Dra., Universidade Federal do Rio Grande do Sul, Brasil <saracopetti@gmail.com> 